\title{
VIEWPOINT
}

\section{About Public Place. A joint work of Behnam Zakeri and Morteza Niknahad}

Behnam Zakeri

behnamzakeri@hotmail.com

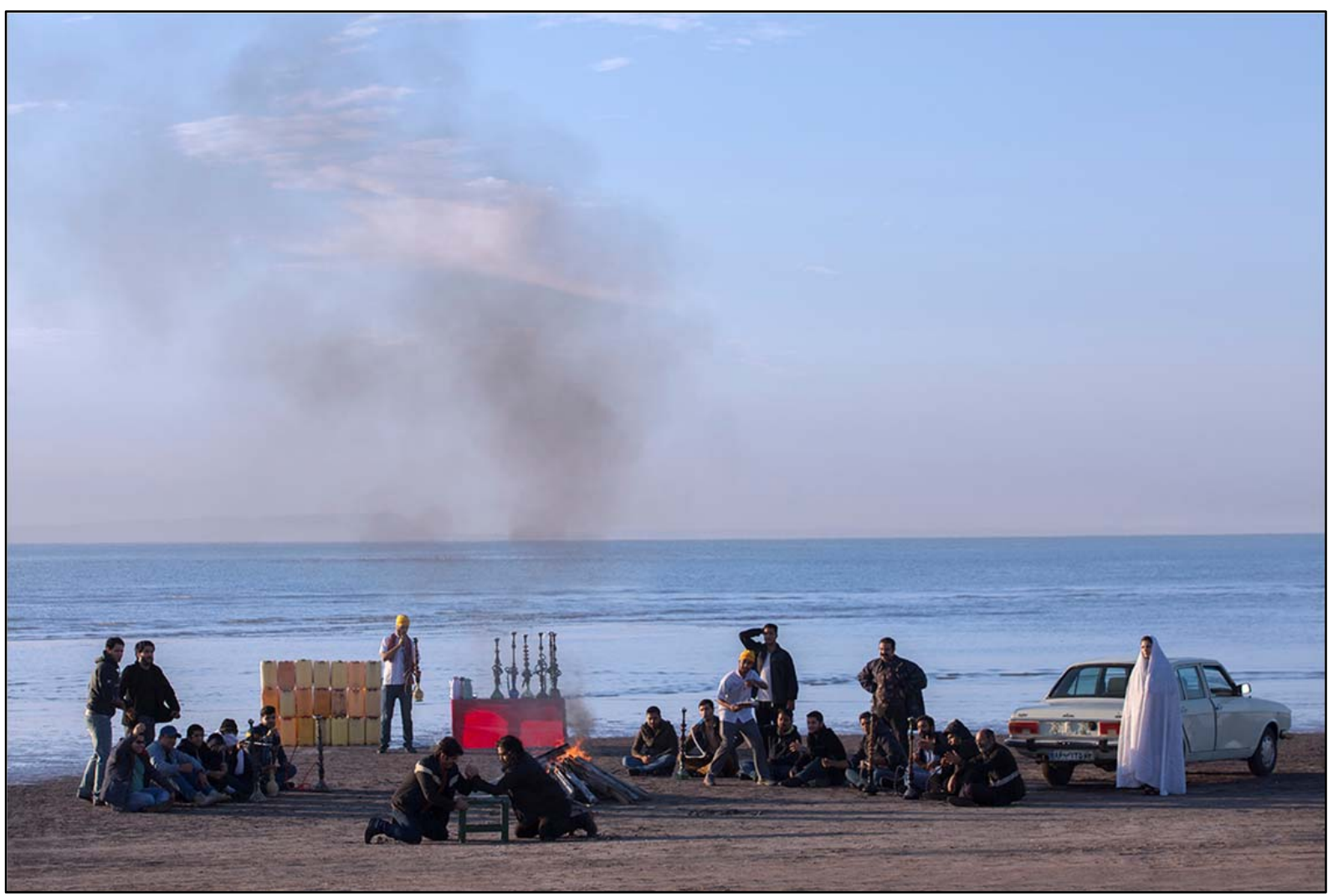

Iran has a special position in the world geographically, politically, socially, culturally and artistically. Mentioned features lead the intellectual and artistic atmosphere of the Iranian community to a certain extent that causes most of the artists to make an inspiration source out of social constraints. In the meantime, many artists choose urban and urban space, many openly criticize the community in the language of art, some are trying to improve the city-human relationship so that people behave the city more responsibly. Urban space identical to generality and accessibility has ever been a channel for many artists. In addition to the city's mysterious mysteries, and the source of plurality of the population, it also occasionally displays a face of stillness and silence. With all its limitations and disadvantages, the city provides an experience of diversity and proliferation of new images; urban space, as it always is visible and accessible, is not 
considered as an important subject, and this could make the urban space invisible. This feature has become a commonplace in the great cities of modern life. For the first time, the cinema depicted the invisible face of the city, a monotonous and routine image that always faces the eyes of the people, now its features and aesthetic appeal have been discovered, and in this direction, the diminutive visual improvisation towards the city became more conscious.

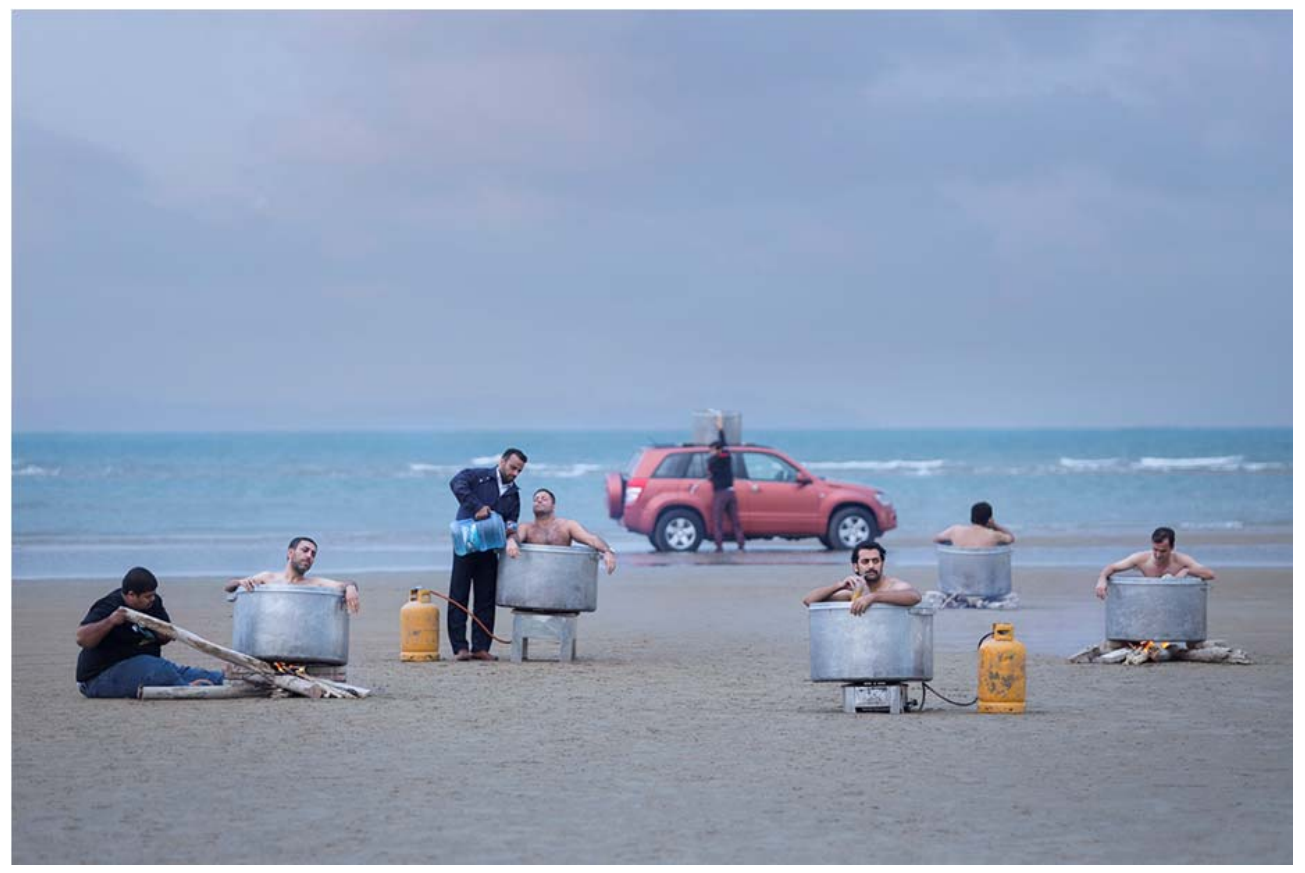

Public Place collection is a joint work by me and Morteza Niknahad which deals with public issues and Iranian society's behaviors in the language of satire. We carried out this project along the seafront applying the idea of overlapping life of dolphins and humans, the closest example to the human beings. Our idea comes from the public places where human behavior changes towards the environment and place, and this duality of human behavior in the personal and public environment was the most important factor in the production of this project.
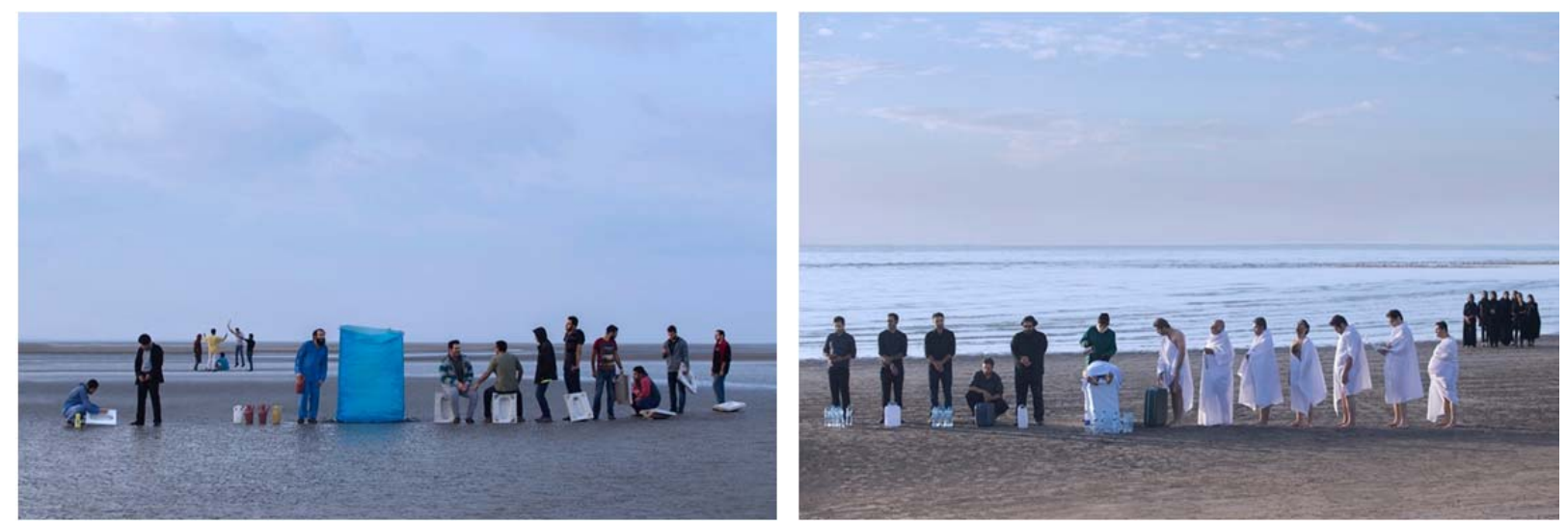

104 | The Journal of Public Space, 2(4), 20I7 | ISSN 2206-9658

(C) Queensland University of Technology 
We started our work in a public space with a focus on the social life of humans, and we made our common ideas in an overwhelming experience through a team work including 150 people.

Our initial idea came from walking along the seafront and it became big and bigger day by day. I have to say that this project is very different from our other works, although in all of our ideas, human beings are the key in the photographs, but an experience of this size has led us to focus on management of our future projects. Working in the public places is an invaluable experience, because existing constraints make it possible to do more creative work and explore different paths to the goal.
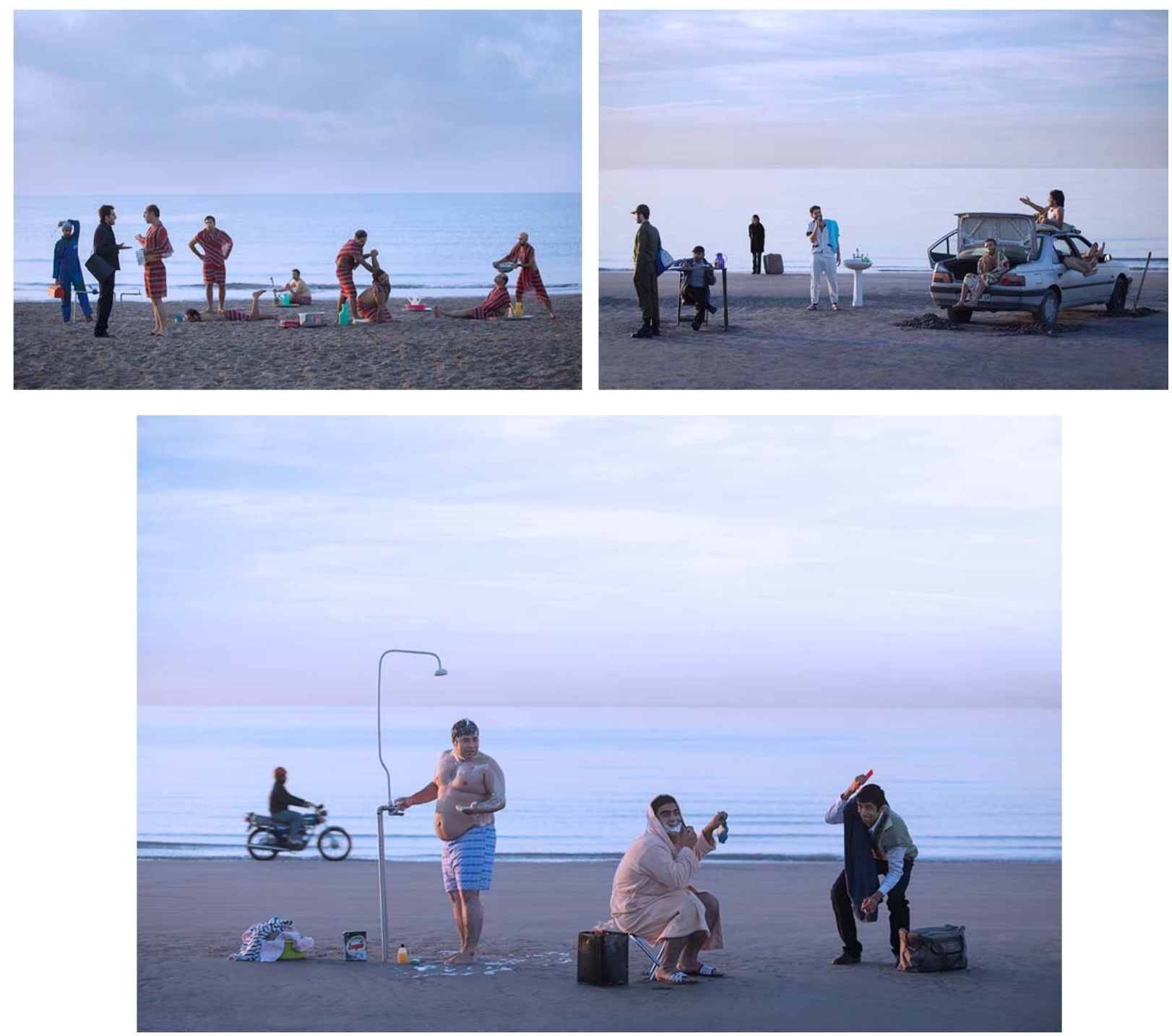

We live and work in Bandar Abbas, a region in southern Iran. This area is of tropical and warm climate, which does not allows you to do such huge work in the public places except in winter.

This experience, though difficult, as a work of art in the public place, was of the pleasing final results. Due to the focus on the space, lack of access to humans and the proper lighting conditions, we shot all the photographs during the dawn. Choosing this time for 
photography and the other hardships faced us with great challenges, including the long process of production.

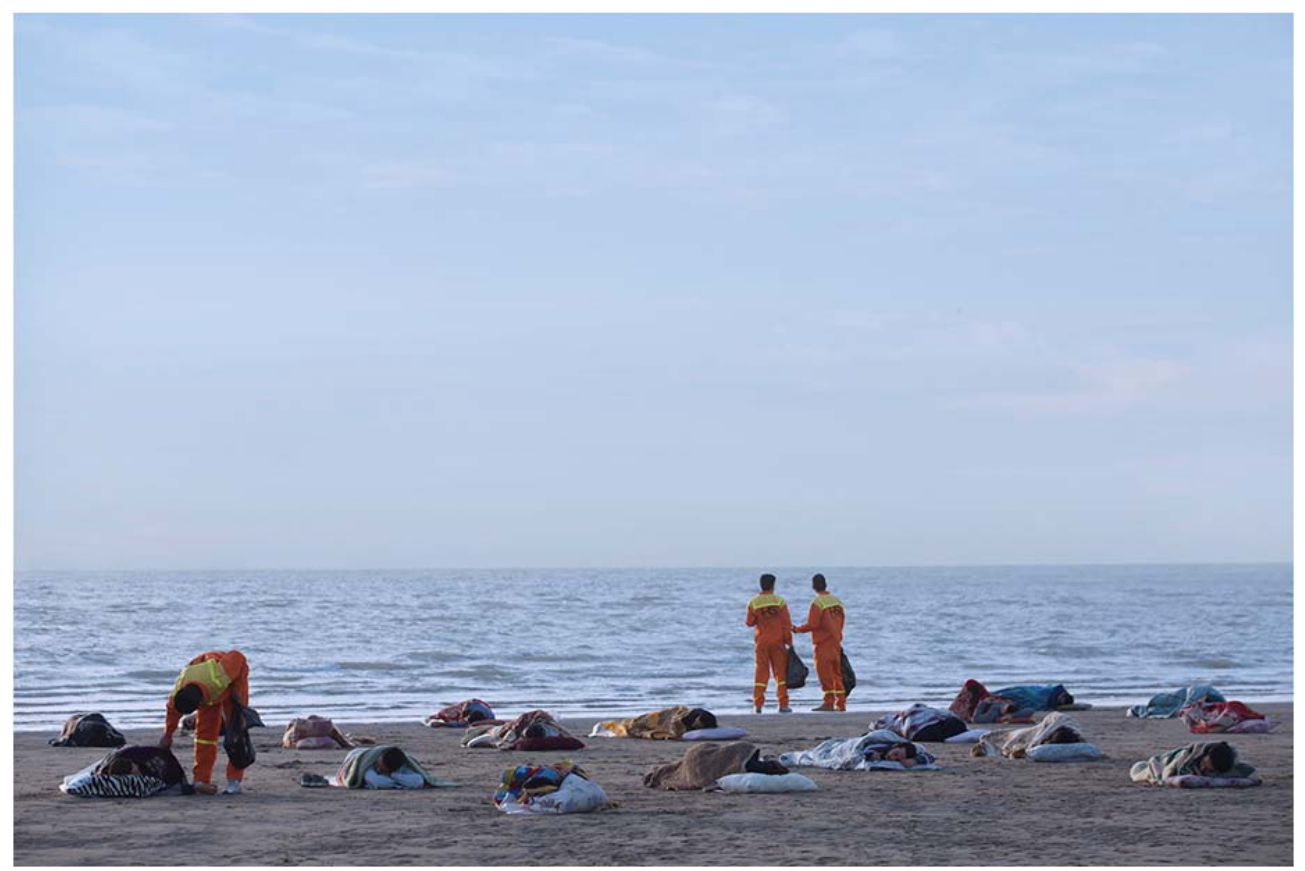

\section{To cite this article:}

Zakeri B. (2017). About Public Place. A joint work of Behnam Zakeri and Morteza Niknahad. The Journal of Public Space, 2(4), I03-I06. DOI: 10.5204/jps.v2i4. I 44

This article has been accepted for publication in The Journal of Public Space. Please see the Editorial Policies under the 'About' section of the journal website for further information.

(c) (i) (-) This work is licensed under a Creative Commons Attribution - Non Commercial 4.0 BY IC International License - https://creativecommons.org/licenses/by-nc/4.0/ 